\title{
Association of fibre density with nutritional quality of the diet in Irish adults aged 18-64 years
}

\author{
S. Bannon, J. Walton and A. Flynn \\ School of Food and Nutritional Sciences, University College Cork, Cork, Republic of Ireland
}

The association between dietary fibre (DF) density and dietary quality was investigated. Analysis was based on the National Adult Nutrition Survey (http://www.iuna.net). A 4-d semi-weighed food diary was used to collect dietary intake data from 1274 adults aged 18-64 y. Dietary intake data were entered into WISP ${ }^{\odot}$, which is based on McCance and Widdowson's The Composition of Foods $6^{\text {th }}$ edition $^{(1)}$ and the Irish food composition database ${ }^{(2)}$. Respondents were split by tertiles of DF density (g/10 MJ), which were stratified by gender and age-group. Food and nutrient intakes were adjusted for total energy (TE). Dietary energy density (DED) was calculated using the 'food only, excluding all beverages' method ${ }^{(3)}$. Intakes of energy, DED and nutrient intakes are reported for the lower and upper thirds of DF density. Statistical differences $(* * P<0.01, * * * P<0.001)$ between upper and lower thirds are reported.

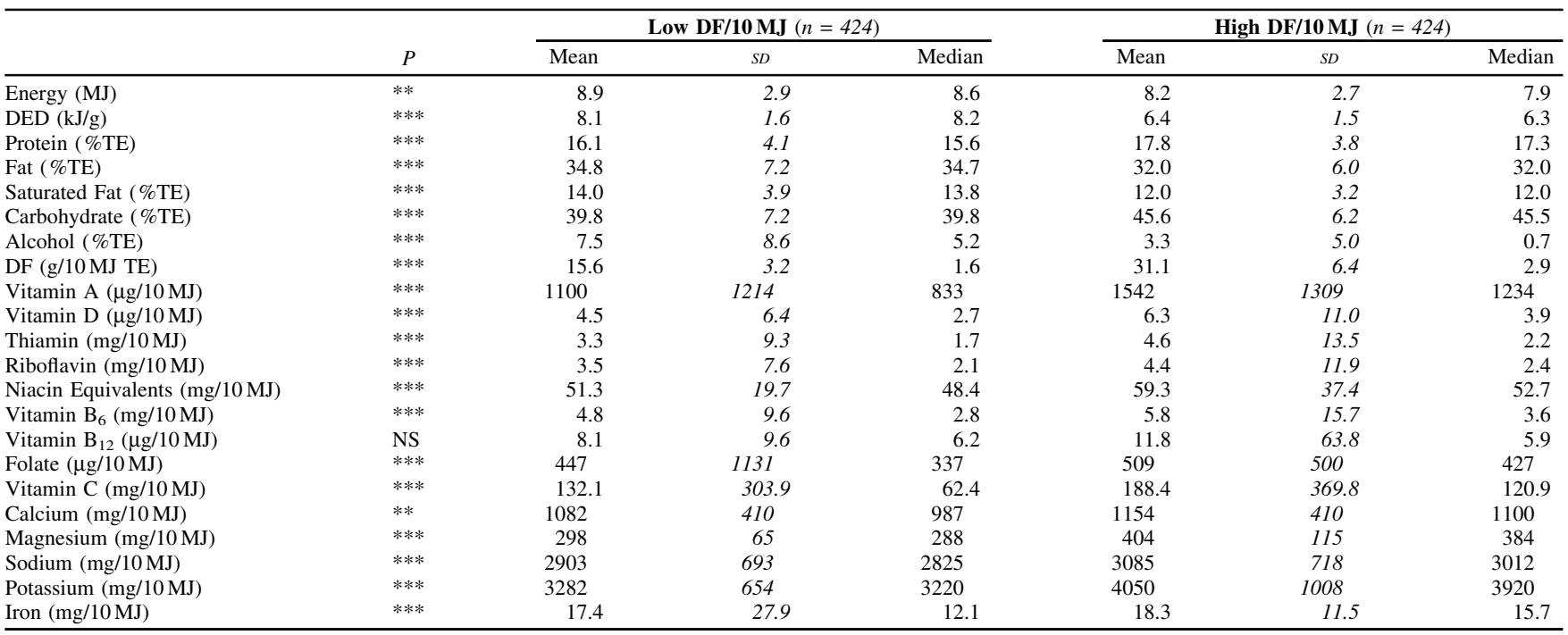

A higher DF density was associated with more favourable macronutrient profiles, a lower DED and greater micronutrient densities in the diet. A higher DF density was also associated with significantly $(P<0.001)$ greater intakes $(\mathrm{g} / 10 \mathrm{MJ})$ of foods such as fruit, vegetables, ready-to-eat breakfast cereals, low fat milk, wholemeal/brown breads and fish, and significantly $(P<0.001)$ lower intakes $(\mathrm{g} / 10 \mathrm{MJ})$ of white bread, whole milk, carbonated beverages (non-diet) and processed meat. In conclusion, a higher DF density was associated with eating patterns more in line with food based dietary guidelines and with better nutritional quality of the diet overall.

The project was funded by the Irish Government under the Food for Health Research Initiative 2007-2012.

1. Food Standards Agency (2002) McCance \& Widdowson's The Composition of Foods Sixth Edition. Cambridge: Royal Society of Chemistry.

2. Black LJ, Ireland J, Møller A et al. (2011) J Food Compost Anal 24(7): 1017-1023.

3. Ledikwe JH, Blanck HM, Khan LK et al. (2005) J Nutr 135, 273-278. 